\title{
Posturas Estáticas de Alongamento no Tratamento da Hiperlordose Lombar: Relato de Casos
}

\author{
Static posture of lengthening in the lumbar hyper lordosis treatment: \\ case reports
}

\author{
ADRIANA MARIA DOS SANTOS MACIEL ${ }^{1}$ \\ MICHELLE DANTAS DE AZEVEDO ${ }^{2}$ \\ ALINE CAVALCANTI BEZERRA ${ }^{3}$ \\ KARINE DANTAS DE AZEVEDO ${ }^{4}$ \\ SANDRA EMÍLIA BENÍCIO BARROS ${ }^{5}$ \\ HELEODÓRIO HONORATO DOS SANTOS ${ }^{5}$ \\ SIMONE DOS SANTOS MACIEL ${ }^{5}$
}

\section{RESUMO}

Objetivo: Avaliar a relação entre o tensionamento do tecido conjuntivo, em virtude da hiperlordose lombar, e o aumento da retenção de líquido, que leva ao consequente aumento da circunferência abdominal. Descrição do caso: Estudo de caráter intervencionista, descritivo e analítico, realizado com oito voluntárias com idade $27 \pm 3$ anos, submetidas a protocolo de avaliação, radiologia, perimetria, ultrassonografia, bioimpedância, análise fotogramétrica e avaliação Postural. Foram realizadas dez sessões de fisioterapia com duração de aproximadamente uma hora cada, sendo utilizadas as posturas estáticas de alongamento para correção da alteração postural. Análise dos dados mediante estatística descritiva, utilizando teste $t$-student, nível de significância $p$ $<0,05$, programas SPSS 13.0; GraphPad Prisma 3.03. Comentários: O líquido corporal apresentou uma variação máxima de aumento de $3,2 \%$, e de redução de $0,4 \%$, e a gordura corporal uma variação máxima de $4,7 \%$. A medida do panículo adiposo, não ultrapassou $5 \mathrm{~mm}$ da medida do primeiro exame.Todas as voluntárias obtiveram melhora significativa da angulação lombossacra $(p=0,025)$. Ao final das intervenções, foi observada uma redução do diâmetro abdominal com média de variação de 2,54 e 2,39 cm nos dois pontos demarcados. Portanto, os resultados sugerem que existe uma correlação importante entre a melhora do funcionamento do sistema linfático e a liberação do tecido conjuntivo, uma vez que ocorreu correção da hiperlordose lombar e melhora da protrusão abdominal.

\section{DESCRITORES}

Postura. Lordose. Alongamento. Sistema Linfático. Fáscia.

\begin{abstract}
Objective: To evaluate if there is a correlation between the tensioning of the conjunctive tissue, as an effect of lumbar hyperlordosis, and an increase in liquid retention resulting in the enlargement of abdominal circumference. Case description: This was an interventionist, descriptive and analytical study, performed with eight volunteers aged $27 \pm$ 3 years. As methods of assessment, radiology, perimetry, ultrasonography, bioimpedance, photogrammetric analyses and postural evaluation were used. Ten sessions of physiotherapy were carried out with duration of approximately one hour each, where the static posture of stretching was used for the correction of the postural alteration. Comments: The corporal liquid presented a maximum variation of increase of $3.2 \%$, and reduction of $0.4 \%$, and the corporal fat had a maximum variation of $4.7 \%$. The measure of the fatty panniculus did not surpass $\pm 5 \mathrm{~mm}$ of the measure of the first exam, before intervention. All patients achieved significant improvement of the lumbo-sacre angle $(p=0,025)$. At the end of the interventions, a reduction of the abdominal diameter was observed with average variation of $2.54 \mathrm{~cm}$ and 2.39 at each demarcated point. Therefore the findings suggest that in all cases there was a correlation between improved functioning of the lymphatic system and tensioning of conjunctive tissue, as can be seen by the correction in the lumbar hyperlordosis and improvement of abdominal protrusion.
\end{abstract}

\section{DESCRIPTORS}

Posture. Lordosis. Elongation. Lymphatic System. Fascia.

\footnotetext{
Docente da Pós-graduação em Fisioterapia Neurofuncional da Faculdade Redentor, Recife/PE, Brasil.

Fisioterapeuta da Clínica Ateliê da Postura, Recife/PE, Brasil.

Fisioterapeuta da Prefeitura Municipal de São Lourenço da Mata, São Lourenço da Mata/PE, Brasil

Docente do Curso de Fisioterapia da Faculdade Estácio de Sá, Recife/PE, Brasil

5 Docente do Departamento de Fisioterapia da Universidade Federal da Paraíba (UFPB), João Pessoa/PB, Brasil.
} 
A fáscia constitui um conjunto membranoso, muito extenso, na qual as estruturas estão ligadas em continuidade, sendo uma entidade funcional que apóia todas as técnicas modernas da terapia manual. A noção de globalidade adotada por terapias manipulativas nos diz que o menor tensionamento, seja ele ativo ou passivo, repercute sobre o conjunto de estruturas, e, portanto, todas as peças anatômicas são consideradas mecanicamente solidárias entre si (CAMARGO et.al., 2002).

Quando se encontra sob tensão, o tecido conjuntivo vai apresentar alteração na substância fundamental, constituída pelos feixes de colágeno podendo se tornar mais densos quando submetidos a estímulos repetitivos que o torna menos elástico, mais compacto e resistente, podendo ter consequências em outros sistemas, tal qual o sistema linfático (ZUCCO, 2002).

O tensionamento do tecido conjuntivo pode ser observado nas disfunções posturais devido a vários fatores, como os vícios posturais, as alterações congênitas ou adquiridas, o sedentarismo, os fatores emocionais e socioculturais, gênero, raça, entre outros (ZUCCO, 2002)

Neste estudo foi dada ênfase à alteração postural denominada hiperlordose lombar, que se caracteriza pela acentuação da curvatura lombar decorrente do desequilíbrio da musculatura dessa região, ou seja, das retrações dos músculos íliopsoas e eretores da coluna, dando uma idéia de "falsa força" e do enfraquecimento dos músculos abdominais (CASTRO, LOPES, 2003)

Um dos métodos utilizados no tratamento dessa alteração postural, hiperlordose, são as posturas estáticas de alongamento, baseadas no alongamento isotônico excêntrico. Alongamento, por se referir ao afastamento da origem e inserção, e isotônico excêntrico por trabalhar exigindo contração muscular, permitindo o ganho de tônus (GUIMARÃES, SACCO, JOÃO, 2007).

Essas posturas consideram o sistema muscular de forma integrada e abordam o indivíduo como um todo, possibilitando colocar todas as cadeias musculares sob tensão, evitando compensações, permitindo o alongamento muscular e de todas as estruturas que estão a sua volta. Desta forma, proporcionam um alongamento mais eficaz, visto que promove uma resposta viscoelástica nos tendões e ativa a síntese protéica (MORENO et. al. 2007).
Dessa forma, surge a hipótese de que a protrusão abdominal, muitas vezes associada a essa alteração postural, não se deve apenas à fraqueza da musculatura abdominal e à desorganização postural, mas também ao mau funcionamento do sistema linfático, que aparenta estar formando um edema de baixo fluxo.

Diante do exposto, este estudo tem como objetivo avaliar se existe correlação entre o tensionamento do tecido conjuntivo, em virtude da hiperlordose lombar, e o aumento da circunferência abdominal, decorrente de um possível acúmulo de líquido nessa região.

\section{RELATO DOS CASOS}

Estudo de casos de caráter intervencionista, descritivo e analítico, realizado com oito voluntárias, do sexo feminino, nulíparas, com dieta sem restrição alimentar, idade $27 \pm 3$ anos, altura variando de 1,62 \pm $2,2 \mathrm{~m}$, e massa corporal entre $65,6 \pm 3,5 \mathrm{~kg}$, portadoras de hiperlordose lombar associada à protrusão abdominal.

A participação das voluntárias ocorreu após esclarecimentos sobre estudo e com assinatura do Termo de Consentimento Livre e Esclarecido (TCLE), após sua aprovação no Comitê de Ética em Pesquisa em Seres Humanos do Hospital Agamenon Magalhães, sob o ${ }^{\circ}$ 22/2009.

Foi utilizada para coleta de dados uma planilha, constando de anamnese; avaliação postural (exame das zonas de retração); análise fotogramétrica, radiológica, ultra-sonografia, bioimpedância e perimetria. Todas as avaliações foram realizadas em duas fases, antes e após dez sessões do tratamento.

As alterações posturais foram avaliadas por meio do exame das zonas de retrações na cabeça e pescoço (zona 1), coluna dorsal (zona 2), coluna lombar (zona 3), pelve (zona 4), joelhos (zona 5) e pés (zona 6), visando identificar qual cadeia muscular se encontra com o maior número alterações e quais posturas serão utilizadas durante a intervenção.

A Análise Fotogramétrica foi realizada com a voluntária na postura ortostática nos planos frontais (anterior e posterior) e sagitais (direito e esquerdo), por 
meio de máquina fotográfica digital (Kodak Easy Share C610),

O exame de ultra-som (US) foi realizado entre a cicatriz umbilical e o púbis, com o intuito de medir a espessura da camada de gordura nessa região. A mensuração foi feita da fáscia do Músculo reto abdominal até o meio da epiderme (RADOMINSKI, 2000).

A bioimpedância bipolar foi realizada por meio da balança digital (Geom), com a finalidade de medir a massa, o percentual de líquido e gordura corporal das voluntárias (TOMASICH et. al,, 2006).

A avaliação radiológica para mensuração do ângulo lombossacro foi realizada no filme através do goniômetro e régua, traçando-se duas retas, uma paralela à parte inferior do filme e a outra tangenciando o promontório sacral, formando o ângulo que quando maior $30^{\circ}$ caracteriza a hiperlordose lombar.

O protocolo de intervenção constou de posturas de alongamento estático das cadeias posterior e anterior realizadas sem carga, com as voluntárias em decúbito dorsal, e com carga, com as voluntárias de pé, associadas à respiração suave e prolongada, numa frequência de duas vezes por semana, com duração de aproximadamente uma hora cada sessão.

Os dados foram avaliados por meio de análise estatística descritiva, utilizando o programa estatístico, Statistical Package for the Social Science (SPSS) versão 16.0 e GraphPad Prism Software, version 3.02.

\section{COMENTÁRIOS}

A variação de massa corporal (figura 1A) observou que apenas duas pacientes apresentaram importante redução do peso (maior que dois quilogramas) sem relato de alteração dos hábitos alimentares, prática de atividade física e de outros tratamentos.

Com relação a variação da porcentagem de líquido corporal apresentou uma variação máxima de aumento de 3,2\%, e de redução de $0,4 \%$ (figura 1B).

Observou aumento da porcentagem de gordura corporal (figura 1C) em apenas duas pacientes, sendo no valor de $0,3 \%$ e $0,5 \%$, em outras cinco houve diminuição, sendo a variação máxima de $4,7 \%$.
De acordo com os achados da ultra-sonografia pode-se verificar que não houve alteração significante da medida do panículo adiposo, pois não ultrapassou cinco milímetros para mais ou para menos da medida do primeiro exame, antes da intervenção (Tabela 1).

O exame das zonas de retração e a análise fotogramétrica mostraram a existência em todas as pacientes de um predomínio de encurtamento nas musculaturas que formam a cadeia anterior, sendo evidenciada principalmente uma projeção cervical anterior; uma retificação dorsal; uma hiperlordose lombar; uma anteversão pélvica; um valgo e recurvatum de joelhos; pés planos (Tabela 2).

Com relação à hiperlordose lombar, percebe-se que apenas uma das oito pacientes teve a completa correção da disfunção, as outras apresentaram melhora, mas continuaram a apresentar encurtamentos musculares nessa região.

A avaliação radiológica confirmou os achados anteriormente citados, em que todas as pacientes obtiveram melhora significativa $(\mathrm{p}=0,025)$ da angulação lombossacra (Figura 2).

Os resultados da perimetria da circunferência abdominal mostram que após a intervenção todas as pacientes apresentaram redução das medidas, com uma média de variação de $2,54 \mathrm{~cm}$, quando observada a mensuração realizada $2,0 \mathrm{~cm}$ acima da cicatriz umbilical e 2,39 cm, no outro ponto em que foi mensurada (Tabela 3). Esses resultados sugerem a melhoria da circulação linfática, que pode ter sido decorrente da liberação tecidual das fáscias, conseguida após o tratamento.

Os resultados sugerem que a melhora da hiperlordose lombar, está relacionada ao alongamento das retrações existentes, associada à diminuição do diâmetro abdominal, confirmando a correlação entre o encurtamento das fáscias musculares e a retenção de líquido na região abdominal.

Diante do exposto, justifica-se a necessidade de mais estudos, com um maior tamanho amostral, enfatizando essa correlação entre as retrações do tecido conjuntivo nas alterações posturais, sobretudo na hiperlordose lombar, e a retenção de líquido na região abdominal, uma vez que o presente trabalho, por se tratar de um relato de apenas oito casos, embora tenha tido resultados positivos, não pode ser extrapolado para a população em geral. 


\section{Massa Corporal}

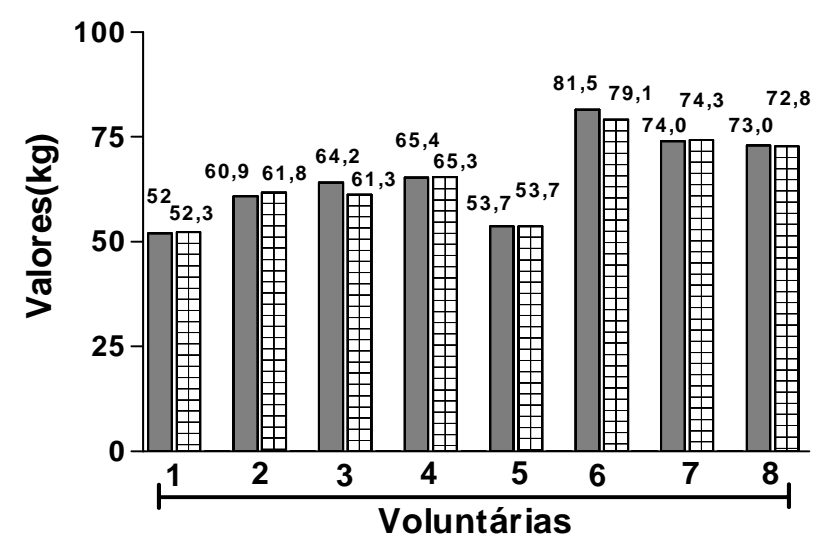

\section{Líquido Corporal}

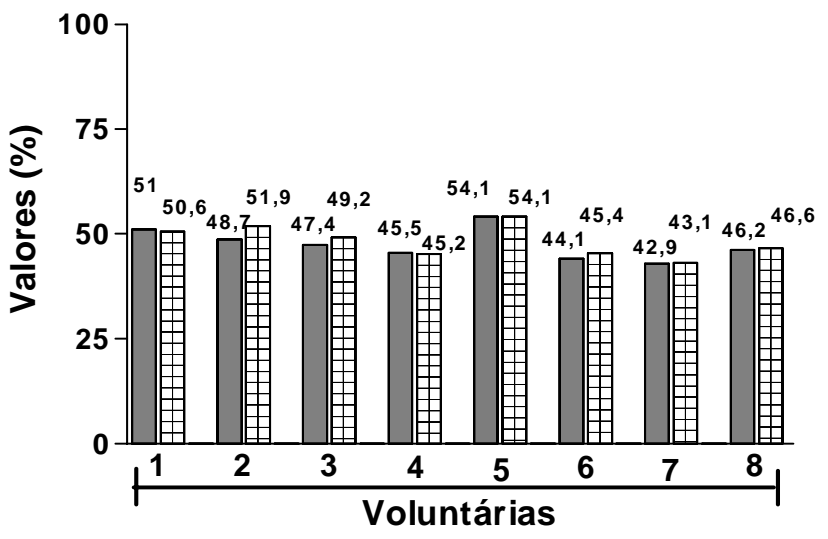

Antes

$\boxplus$ Após

\section{Gordura Corporal}

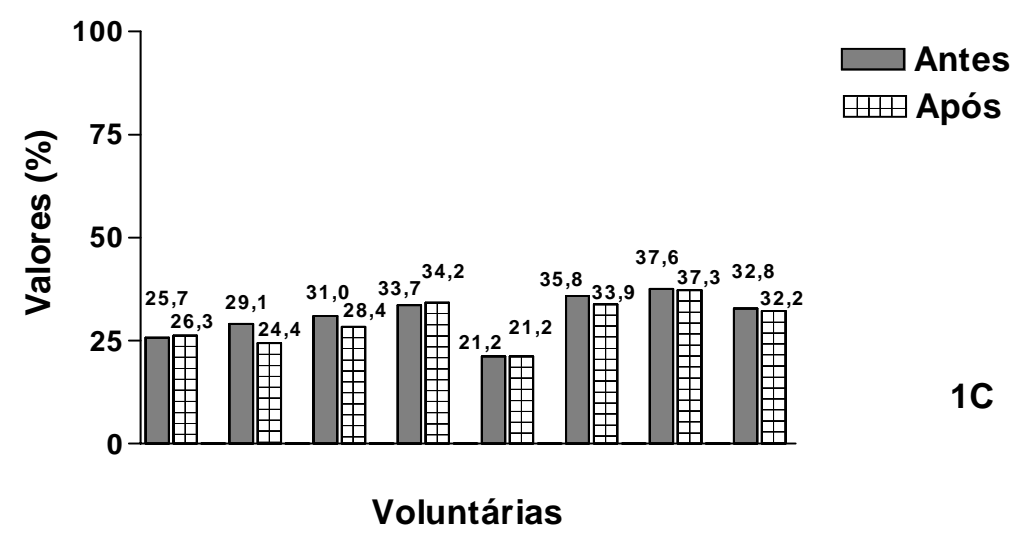

Figura 1 - Variação da massa corporal (1A); da porcentagem de líquido corporal (1B) e de gordura corporal (1C) das voluntárias avaliadas por meio da bioimpedância antes e após intervenção. 
Tabela 1. Valores da mensuraçảo da espessura do paniculo adiposo por meio da ultra-sonografia, antes $e$ apos a intervenç大o

\begin{tabular}{c|c|c}
\hline \multirow{2}{*}{ Voluntárias } & Espessura do paniculo adiposo (mm) \\
\cline { 2 - 3 } & Antes & Após \\
\hline 1 & 25,1 & 25,3 \\
2 & 22,3 & 23,1 \\
3 & 32,2 & 31,5 \\
4 & 32,9 & 34,8 \\
5 & 17,1 & 15,3 \\
6 & 36,9 & 39,6 \\
7 & 37,0 & 42,0 \\
8 & 39,1 & 39,5 \\
\hline
\end{tabular}

\begin{tabular}{|c|c|c|c|c|c|c|c|c|}
\hline \multirow{3}{*}{ Zona } & \multicolumn{8}{|c|}{ Cadeias musculares (\%) } \\
\hline & \multicolumn{4}{|c|}{ Antes } & \multicolumn{4}{|c|}{ ADós } \\
\hline & Anterior & Posterior & Mista & $\begin{array}{l}\text { Sem } \\
\text { retracāo }\end{array}$ & Anterior & Posterior & Mista & $\begin{array}{l}\text { Sem } \\
\text { retracão }\end{array}$ \\
\hline 1 & 62.5 & 0 & 37.5 & 0 & 12,5 & 0 & 0 & 87.5 \\
\hline 2 & 0 & 87.5 & 0 & 12.5 & 0 & 87.5 & 0 & 12.5 \\
\hline 3 & 0 & 0 & 100 & 0 & 0 & 0 & 87.5 & 12.5 \\
\hline 4 & 100 & 0 & 0 & 0 & 87.5 & 0 & 0 & 12.5 \\
\hline 5 & 0 & 0 & 100 & 0 & 25 & 0 & 75 & 0 \\
\hline 6 & 50 & 0 & 0 & 50 & 37.5 & 0 & 0 & 62.5 \\
\hline
\end{tabular}

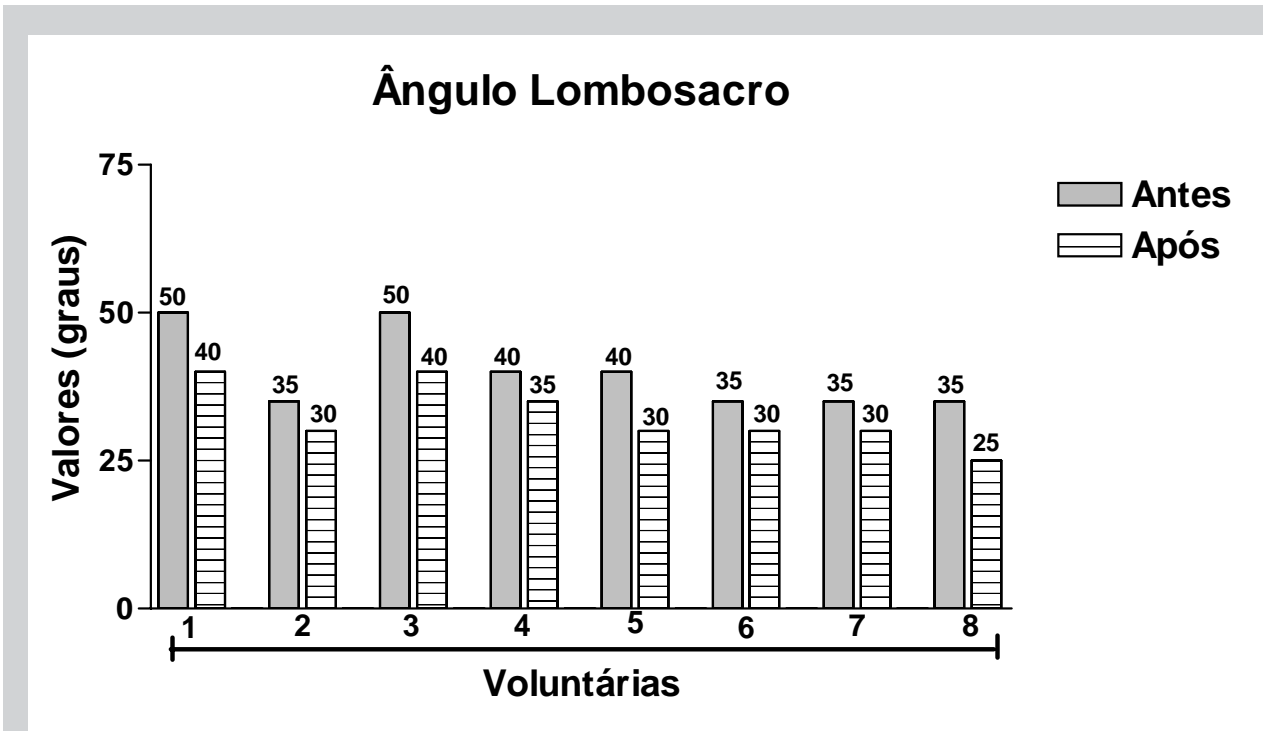

Figura 2 - Variação dos valores do ângulo lombossacro (graus) avaliados por meio de radiografia das pacientes antes e após intervenção. 
Tabela 3 - Resultados da perimetria realizada $2,0 \mathrm{~cm}$ acima e abaixo da cicatriz umbilical antes e após o tratamento

\begin{tabular}{|c|c|c|c|c|c|c|}
\hline \multicolumn{7}{|c|}{ Perimetria (cm) } \\
\hline \multirow[t]{2}{*}{ Voluntárias } & \multicolumn{3}{|c|}{$\begin{array}{c}2,0 \mathrm{~cm} \text { acima da cicatriz } \\
\text { umbilical }\end{array}$} & \multicolumn{3}{|c|}{$2,0 \mathrm{~cm}$ abaixo da cicatriz umblical } \\
\hline & Antes & Após & Variaçâo & Antes & Após & Variaçăo \\
\hline 1 & 76.5 & 76.2 & $\downarrow 0,3$ & 85 & 83,3 & $\downarrow 2,2$ \\
\hline 2 & 71 & 70 & $\downarrow 1,0$ & 84.1 & 80 & $\$ 4.1$ \\
\hline 3 & 86 & 80.5 & $\downarrow 5.5$ & 92.5 & 87,2 & $\downarrow 5.3$ \\
\hline 4 & 87.2 & 83.5 & $\downarrow 3,7$ & 91,6 & 90.6 & $\downarrow 1,0$ \\
\hline 5 & 70.5 & 68.5 & $\downarrow 2,0$ & 79.5 & 78.5 & $\downarrow 1,0$ \\
\hline 6 & 88.5 & 85 & $\downarrow 3,5$ & 94.5 & 93.9 & $\downarrow 0,6$ \\
\hline 7 & 95,7 & 94 & $\downarrow 1,7$ & 99.3 & 97,5 & $\downarrow 1,8$ \\
\hline 8 & 83.1 & 80.5 & $\downarrow 2.6$ & 92.6 & 89.5 & $\downarrow 3,1$ \\
\hline
\end{tabular}

\section{REFERÊNCIAS}

1. CAMARGO DF, BEIER GS, BEZERRAKA, GODINHO MCN, Araújo ST. Análise do músculo reto abdominal. Revista digital vida \& saúde. 2002; 3(1).

2. CASTRO PCG, LOPES JAF. Avaliação computadorizada por fotografia digital, como recurso de avaliação na Reeducação Postural Global. Acta Fisiátrica. 2003; 2(10): 83-88.

3. GUIMARÃES MMB, SACCO ICN, JOÃO SMA. Caracterização postural da jovem praticante de ginástica olímpica. Revista Brasileira de Fisioterapia. 2007; 3(11): 213-219.

4. MORENO MA, CATAI AM, TEODORI RM, BORGES, BLA, CESAR MC, SILVA E. Efeito de um programa de alongamento muscular pelo método de Reeducação Postural Global sobre a força muscular respiratória e a mobilidade toracoabdominal de homens jovens sedentários. Jornal Brasileiro de Pneumologia. 2007; 33(6): 679-686.

5. RADOMINSKI RB, VEZOZZO DP, CERRI GG, HALPERN A. O uso da ultra-sonografia na avaliação da distribuição de gordura abdominal. Arquivo Brasileiro de Endocrinologia \& Metabologia. 2000; 44(1): 5-12.
6. TOMASICH FDS, DIAS AA, SIMÕES MLPB, PACHECO AM, COSTA PB, PIECHNIK J. Modelo experimental de icterícia obstrutiva. Avaliação por meio da bioimpedância. Rev. Col. Bras. Cir. 2006; 33(1):1518.

7. ZUCCO F. A drenagem linfática e sua aplicabilidade nos períodos de mudança hormonal. Fisio \& Terapia. 2002; 6(35): $30-32$.

Correspondência

Adriana Maria dos Santos Maciel.

Rua Conselheiro Nabuco, 360, apto 203, Casa Amarela

Recife - Pernambuco.- Brasil.

CEP 52051-440

Tel: (81) 92898797

Email:macieladriana@hotmail.com 